\title{
Intraocular lens implants for uniocular cataracts in childhood
}

\author{
J P BURKE,' H E WILlSHAW, 2 AND J D H YOUNG'
}

From the 'Department of Ophthalmology, Ninewells Hospital and Medical School, Dundee, and ${ }^{2}$ Department of Paediatric Ophthalmology, Children's Hospital, Ladywood, Birmingham

SUMMARY We report the outcome of intraocular lens implantation in 20 children with visually significant cataracts (seven traumatic, 13 non-traumatic). Six patients had anterior and 14 had posterior chamber implants. The mean age of the whole group at the time of surgery was 5.9 years (range 0.3 to 15.1 years), while the mean period of follow-up was 2.4 years (range 0.8 to 5.9 years). Postoperatively 10 patients developed a transient fibrinous uveitis, four required lens repositioning, one needed lens removal, and eight required posterior capsulotomy. Complications warranting secondary surgical procedures occurred predominantly in eyes with posterior chamber implants. Co-operation with conventional amblyopia treatment was satisfactory in eight out of 16 patients. Postoperatively nine out of 18 patients had peripheral fusion, four patients regained visual acuities of better than 6/9, and visual acuity did not improve beyond 3/60 in six cases. In 19 eyes the optical pathway to the retina is clear and the implants are stable with no evidence of persisting inflammation. Contact lenses remain the initial treatment of choice in infancy, but modern intraocular lenses are well tolerated and have a role in the visual rehablitation of patients with contact lens and probable contact lens failures and older children with uniocular cataracts.

Before the early 1980 s the child with a monocular congenital cataract was considered a virtually hopeless clinical problem, with successful visual rehabilitation practically unknown. ${ }^{-4}$ But some recent studies show that such patients may benefit from early cataract extraction and intensive occlusion therapy initiated during the critical period for development of visual perception..$^{-4 x}$ While sometimes very rewarding, the successful management of these children is none the less difficult, time consuming, and requiring much compliance from the patient and motivation in the parents. A contact lens is the generally accepted treatment ${ }^{9}$ "1 but is often given up or associated with complications. ${ }^{11-13}$

In selected cases implantation of an intraocular lens (IOL) is an alternative, and encouraging results have been reported in patients with traumatic and monocular congenital cataracts. ${ }^{1418}$ However, enthusiasm for this form of therapy has been tempered by initial discouraging results, ${ }^{19}$ complications specifically related to paediatric pseudoCorrespondence to Mr J D H Young, Ward 24/25, Ninewells Hospital, Dundee DD1 9SY. phakia, ${ }^{2021}$ and the possibility of secondary complications many years after implantation. Recent advances in microsurgical techniques and intraocular lens design plus the availability of hyaluronidase and the neodymium (Nd) - YAG laser have reduced operative complications and facilitated their treatment. ${ }^{22} 2.3$

We chose to implant posterior chamber and flexible one-piece anterior chamber lenses in a selected series of children with unilateral aphakia, believing that complications from an intraocular lens would be less significant than the inevitable severe amblyopia of inadequately treated cases.

\section{Subjects and methods}

We studied a consecutive series of 20 children who were treated with intraocular lenses following the removal of uniocular cataracts. Seven had traumatic cataracts and 13 infantile cataracts of uncertain aetiology. Informed consent was obtained from the parents of each child in the study. The parents were given information on the risks, benefits, and alternatives to the procedure. Patients with non-traumatic 
cataract were selected for secondary lens implantation after failure with a contact lens or for primary intraocular lens implantation if the parent or child refused contact lens wear, or the ophthalmologist deemed that contact lens wear would not be successfully concluded owing to non-compliance of parent or patient, or owing to other social factors which precluded adequate contact lens follow-up and replacement. Patients with traumatic cataracts either had cataract surgery and IOL implantation in conjunction with reconstitution of the globe or as a second procedure when intraocular inflammation had settled.

Eighteen of our patients underwent lens aspiration with (4) or without (14) primary posterior capsulotomy. Fifteen of these had J-loop posterior chamber intraocular lenses (PC IOL) with prolene loops and three patients (cases 9, 15, 20) had flexible one-piece open loop polymethyl methacrylate (PMMA) anterior chamber lenses (AC IOL). Two patients after ocutome lensectomy (cases 2 and 8 ) also had secondary anterior chamber intraocular lenses implanted. Where possible in older children intraocular lens powers were calculated from keratometer readings, A-scan axial lengths, anterior chamber depths, and refractive errors. A standard adult powered lens of between +19 dioptres and +21 dioptres was placed in children less than 3 years old, because of inaccuracies induced by growth of the eye.

Postoperatively, the patients were regularly examined by an ophthalmologist and orthopist. Visual acuities before and after surgery were measured by the Stycar, Sheridan-Gardiner, or Snellen tests, and by acuity card procedure, or by observing ocular motor fixation patterns in patients too young to respond to subjective visual testing. When indicated, neodymium-YAG laser posterior capsulotomy was performed, generally with ease, in patients over 6 years old, while younger children usually required operative discission under general anaesthesia.

\section{Results}

The mean age of the 20 children (Table 1) at the time of intraocular lens implantation was 5.9 years (range $0 \cdot 3$ to $15 \cdot 1$ years), while the mean age of the traumatic and non-traumatic groups was 8.8 and 4.4 years respectively. The level of pre-and postoperative acuities for both groups is shown in Table 2. Docu-

Table 1 Patient data

\begin{tabular}{|c|c|c|c|c|c|c|c|c|c|c|}
\hline \multirow{2}{*}{$\begin{array}{l}\text { Patient } \\
\text { no. }\end{array}$} & \multirow{2}{*}{$\begin{array}{l}\text { Age at } \\
\text { IOL } \\
\text { surgery } \\
\text { (years) }\end{array}$} & \multirow{2}{*}{$\begin{array}{l}\text { Length } \\
\text { of } \\
\text { follow- } \\
\text { up } \\
\text { (years) }\end{array}$} & \multirow{2}{*}{$\begin{array}{l}\text { Aetiology } \\
\text { of } \\
\text { cataract }\end{array}$} & \multirow{2}{*}{$\begin{array}{l}\text { Type and } \\
\text { power of } \\
\text { implant }\end{array}$} & \multirow{2}{*}{$\begin{array}{l}\text { Surgical } \\
\text { technique }\end{array}$} & \multicolumn{2}{|c|}{ Visual acuity } & \multirow{2}{*}{$\begin{array}{l}\text { Post } \\
\text { operative } \\
\text { peripheral } \\
\text { fusion }\end{array}$} & \multirow{2}{*}{$\begin{array}{l}\text { Compliance } \\
\text { with } \\
\text { occlusion }\end{array}$} & \multirow{2}{*}{$\begin{array}{l}\text { Refraction within } \\
I \cdot 5 \text { years of surgery }\end{array}$} \\
\hline & & & & & & Preop. & Current & & & \\
\hline $1^{*}$ & $12 \cdot 7$ & $1 \cdot 4$ & $\mathrm{~T}$ & PC 20D & Asp. & $6 / 60$ & $6 / 6$ & + & & $-0.75+1.0 \times 15$ \\
\hline 2 & $3 \cdot 4$ & $3 \cdot 6$ & $\mathrm{~T}$ & $\mathrm{AC} 20 \mathrm{D}$ & $\mathrm{OL} \ddagger$ & $1 / 60$ & $6 / 24$ & $+*$ & Fair & $-1 \cdot 50+3 \cdot 0 \times 120$ \\
\hline $3 *$ & $6 \cdot 4$ & $2 \cdot 0$ & NT & $\begin{array}{l}(\mathrm{PC})^{\dagger} \\
\mathrm{AC} 21 \mathrm{D}\end{array}$ & Asp. & $3 / 60$ & $6 / 60$ & $\S$ & Poor & $+3 \cdot 0+0.5 \times 160$ \\
\hline $4^{*}$ & $1 \cdot 7$ & $4 \cdot 4$ & NT & PC 23D & Asp. & UCUSUM & $3 / 60$ & $\S$ & Fair & $-3 \cdot(0+2 \cdot 0 \times 120$ \\
\hline $5 *$ & $1 \cdot 4$ & $5 \cdot 7$ & NT & PC 21D & Asp. & UCUSUM & $6 / 24$ & + & Good & $-2 \cdot 5+2 \cdot 0 \times 110$ \\
\hline $6^{*}$ & $4 \cdot 7$ & $2 \cdot 2$ & NT & PC 19D & Asp. & UCUSUM & $3 / 60$ & $\S$ & Fair & $-1 \cdot 50+0.25 \times 160$ \\
\hline $7 *$ & $7 \cdot 9$ & $1 \cdot 1$ & NT & PC 22D & Asp. & $\mathrm{PL}$ & $2 / 60$ & & Poor & $+1 \cdot 50$ \\
\hline 8 & $6 \cdot 0$ & $2 \cdot 1$ & $\mathrm{~T}$ & $\mathrm{AC} 22 \mathrm{D}$ & OL $\ddagger$ & $6 / 36$ & $2 / 60$ & + & Poor & $+2 \cdot()+1 \cdot(0 \times 90$ \\
\hline $9 *$ & $5 \cdot 2$ & $1 \cdot 3$ & NT & $\mathrm{AC} 21 \mathrm{D}$ & Asp. & $2 / 60$ & $6 / 36$ & $+*$ & Fair & $+3 \cdot 0+2 \cdot 0 \times 80$ \\
\hline $10^{*}$ & $15 \cdot 1$ & $1 \cdot 1$ & $\mathrm{~T}$ & PC 20D & Asp. & $\mathrm{HM}$ & $6 / 9$ & + & & $-0.5+1.25 \times 180$ \\
\hline $11^{*}$ & $0 \cdot 3$ & 5.9 & NT & PC 21D & Asp. \& $C \ddagger$ & UCUSUM & PL & $\S$ & Poor & IOL removed \\
\hline 12 & $12 \cdot 1$ & $1 \cdot 2$ & NT & PC 19D & Asp. & $6 / 36$ & $6 / 9$ & + & & $+2.25+0.75 \times 130$ \\
\hline 13 & $6 \cdot 9$ & 0.8 & NT & PC 21D & Asp. & $1 / 60$ & $5 / 60$ & $\S$ & Fair & $-3 \cdot 50+2 \cdot 0 \times 150$ \\
\hline $14^{*}$ & $3 \cdot 0$ & $1 \cdot 6$ & NT & PC 21D & Asp. & $6 / 36$ & $3 / 60$ & & Poor & $-1.50+1.75 \times 80$ \\
\hline 15 & $4 \cdot 5$ & $2 \cdot 3$ & $\mathrm{~T}$ & AC 19D & Asp. & HM & $2 / 60$ & & Good & $-1 \cdot 50$ \\
\hline $16^{*}$ & $12 \cdot 4$ & 1.9 & $\mathrm{~T}$ & PC 21D & Asp. & $1 / 60$ & $6 / 18$ & + & & $-1 \cdot(0+2 \cdot 75 \times 150$ \\
\hline 17 & $0 \cdot 8$ & 1.9 & NT & PC 21D & Asp. \& C & UCUSUM & PL & NA: & Poor & $+7 \cdot 50$ contact lens \\
\hline 18 & 0.5 & $4 \cdot 3$ & NT & PC 21D & Asp. \& C & UCUSUM & $2 / 60$ & $\S$ & Poor & $-2 \cdot 50$ \\
\hline 19 & $6 \cdot 0$ & $1 \cdot 7$ & NT & PC 21D & Asp. \& C & $4 / 60$ & $6 / 36$ & NA & Good & $-0.75+1.0(0) \times 16.5$ \\
\hline 20 & $7 \cdot 7$ & $1 \cdot 6$ & $\mathrm{~T}$ & $\mathrm{AC} 23 \mathrm{D}$ & Asp. & PL & $6 / 4$ & + & Good & $-1.75+1.25 \times 9.5$ \\
\hline
\end{tabular}

$\mathrm{T}=$ traumatic. $\mathrm{NT}=$ non-traumatic. $\mathrm{PC}=$ posterior chamber $\mathrm{IOL} . \mathrm{AC}=$ anterior chamber IOL. Asp. $=$ lens aspiration. $\mathrm{C}=$ posterior capsulotomy. $\mathrm{OL}=$ ocutome lensectomy. $\mathrm{PL}=$ perception of light. $\mathrm{HM}=$ hand movements. UCUSUM=uncentral, unsteady, unmaintained fixation, considered equivalent to $<1 \cdot 5 / 60 . \mathrm{NA}=$ not available. Patient $11=$ microphthalmos and nystagmus. Patient $18=$ microphthalmos and congenital syphillis. $+=$ present.

*Patients who require secondary surgical procedures. †PC IOL replaced by AC IOL. $\ddagger$ Contact lens failure. $₫$ Strabismus. 
mented preoperative heterotropia was present in six cases; two eyes were microphthalmic (cases 11 and 18 ), but no patient had nystagmus. One child (case 2) had an ocutome lensectomy, contact lens, and penetrating keratoplasty at the age of 2 years after a penetrating corneal injury.

The most frequent early postoperative complications was a fibrinous uveitis, which usually began after 24 hours and required topical corticosteroids (Table 3). One patient (case 8) had a small hyphaema, and one had transient superior half corneal oedema (case 6). During the mean follow-up period of 2.4 years (AC IOL 2.1 years, PC IOL 2.5 years) the majority of complications occurred in cases with posterior chamber intraocular lens implants (Table 3 ). These were iris implant synechiae and visually significant posterior capsular opacification. Eight patients (Table 4) required surgical or Nd-YAG laser capsulotomies, one of whom (case 18) had already had a primary capsulotomy. Five cases had the PC IOL haptic dislocated and held forward in the irispupil plane by synechiae. Three of these had an uneventful repositioning of the PC IOL haptic with no recurrence, and one patient (case 3 ) had the PC IOL replaced without difficulty by an AC IOL with no subsequent complications. One patient (case 11) had the PC IOL removed and replaced by a contact lens.

None of our patients had cystoid macular oedema clinically, though fluorescein angiography was not performed. Retinoscopy after operation showed low degrees of hypermetropia or myopia in most cases (Table 1). One patient (case 17) had a significant anisometropia requiring a $+7 \cdot 5$ dioptre overcorrection with a contact lens at six months. There was only one case of postoperative astigmatism greater than 2.75 dioptres, and this occurred in a patient (case 2) who had a previous corneal graft. Sixteen patients were on intensive occlusion therapy postoperatively (up to seven hours per day) with variable compliance and visual rehabilitation (Table 1). It was possible to test fusion potential in 18 patients by means of a synoptophore, nine of whom showed variable degrees of peripheral fusion.

\section{Discussion}

The visual results following removal of monocular cataracts from infants' eyes are often disappointing. Though the prognosis for attainment of good acuity and fusion in older children is poorer, surgery should be considered in selected cases, as it may be impossible to date the onset of cataract and visual deterioration with any degree of precision. ${ }^{2+}$ Untreated until adult life these patients may have acuities of perception of light only. ${ }^{25}$ Even an acuity of $1 / 60$ represents a significant improvement on this for a reserve eye. Only two patients in this series have a current acuity poorer than $1 / 60$.

Contact lenses, the standard optical treatment, are associated with many problems. These include infections, sterile inflammations, ${ }^{26}$ and induction of morphological changes in the epithelium ${ }^{27}$ and endothelium. ${ }^{2 \times}$ In addition, many parents are unable to cope with the care of their childrens' long-term contact lens, which can be a source of considerable stress to both the child and family.

Epikeratophakia is an alternative option in cases unsuitable for contact lense wear. One problem of this procedure has been the slow return of visual function to preoperative levels owing to gradual clearing of the tissue lens in patients who are already amblyopic. Recent studies ${ }^{29}{ }^{3.11}$ have yielded encouraging results in patients less than 18 years old.

Table 2 Present and preoperative acuities of patients with traumatic and non-traumatic uniocular cataracts

\begin{tabular}{|c|c|c|c|c|}
\hline \multirow[t]{2}{*}{ Visual acuity } & \multicolumn{2}{|l|}{$\begin{array}{l}\text { Traumatic (7) } \\
\text { Visual acuity }\end{array}$} & \multicolumn{2}{|c|}{$\begin{array}{l}\text { Non-traumatic (13) } \\
\text { Visual acuity }\end{array}$} \\
\hline & Preoperative & Current & Preoperative & Current \\
\hline$\leqslant 6 / 9$ & - & 3 & - & 1 \\
\hline $6 / 12-6 / 36$ & 1 & 2 & 2 & 3 \\
\hline $6 / 60-3 / 60$ & 1 & - & 2 & 5 \\
\hline $2 / 60-1 / 60$ & 2 & 2 & & 2 \\
\hline$<1 / 60$ & 3 & - & 9 & 2 \\
\hline
\end{tabular}

Table 3 Postoperative intraocular lens complications

\begin{tabular}{lll}
\hline Complications & $\begin{array}{l}\text { Anterior chamber } \\
\text { implants } 5 \text { cases) }\end{array}$ & $\begin{array}{l}\text { Posterior chamber } \\
\text { implants } \text { (15 cases) }\end{array}$ \\
\hline $\begin{array}{l}\text { Fibrinous uveitis } \\
\text { Visually significant }\end{array}$ & 3 & 7 \\
$\quad \begin{array}{l}\text { posterior capsule } \\
\text { opacities }\end{array}$ & - & \\
Iris - implant synechiae & - & 6 \\
Iris sphincter erosion & - & 9 \\
\hline
\end{tabular}

Table 4 Secondary surgical procedures

\begin{tabular}{lll}
\hline Procedure & $\begin{array}{l}\text { Anterior chamber } \\
\text { lens }(5 \text { cases) }\end{array}$ & $\begin{array}{l}\text { Posterior chamber } \\
\text { lens }(15 \text { cases) }\end{array}$ \\
\hline $\begin{array}{lll}\text { Posterior capsulotomy } \\
\text { (surgical/Nd-YAG) }\end{array}$ & - & 8 \\
$\begin{array}{l}\text { IOL repositioning } \\
\text { IOL replacement }\end{array}$ & - & 3 \\
$\begin{array}{l}\text { IOL removal and } \\
\text { pupilotomy }\end{array}$ & - & $1^{*}$ \\
\hline
\end{tabular}

*Posterior chamber implant replaced by an anterior chamber implant. 
So far, however, no controlled trial in children comparing epikeratophakia with intraocular lens implantation has been carried out.

In adults intraocular lens implantation is superior to contact lenses in achieving good binocular function. ${ }^{31}$ However, ophthalmologists continue to disagree about lens implantation in children. Some stress their usefulness, other consider them impracticable. Hiles has shown that non-compliance by the patient in accepting the best optical correction is lower in those who have an intraocular lens than in those with a contact lens, though compliance in accepting occlusion for amblyopia remains an equal problem in both groups. ${ }^{13}$

The effect of intraocular lenses on the growth, development, and structures of the child's eye remains speculative, but a recent study ${ }^{32}$ described their short-term safety and predictability, finding no histopathological evidence that the child's eye tolerated an intraocular lens less well than an adult's. Our 20 cases represent a heterogeneous group of traumatic and non-traumatic uniocular cataracts. The visual results were encouraging in that nine of 18 patients assessed had peripheral fusion, four had final acuities of better than or equal to $6 / 9$, while the acuity of six patients measured $<3 / 60$. Intraocular lenses were generally well tolerated and anatomically stable in 19 eyes, with no evidence of persisting inflammation.

We found that the prevalence of postoperative complications, particularly visually significant posterior capsular opacification and early postoperative lens malposition (Table 3), to be higher in children with posterior chamber implants. By contrast, a smaller group who had flexible anterior chamber implants were relatively free of pupil complications irrespective of the presence or absence of the posterior capsule. Hiles and Hered report a similar trend in a larger group of patients. ${ }^{23}$ They found that secondary membranes and lens malposition occurred in $22 \%$ and $7 \%$ respectively of eyes with anterior chamber inplants compared with $63 \%$ and $40 \%$ in eyes with posterior chamber implants. They also note that secondary membranes developed earlier in eyes with posterior chamber implants.

Like others we evaluate the best optical correction in the context of the dynamic growth of the eye and the changes in refractive power that occur throughout childhood. In our experience the preferred treatment for the infant with compliant parents is lensectomy or lens aspiration plus capsulotomy, contact lens wear, and intensive occlusion therapy. There are nevertheless patients within this group who fail to achieve adequate contact lens wear, with many episodes of interrupted treatment and a poor visual outcome. We consider that they form a particular indication for secondary anterior chamber lens implantation in the hope of a least retaining useful peripheral vision. One of our patients (case 2) who was intolerant of a contact lens remained binocular with useful vision following intraocular lens implantation. Likewise, patients with uniocular traumatic or late-onset developmental cataracts, who may have already developed binocularity, could be considered for intraocular lens implantation (Table 2), as high power aphakic contact lenses may induce sufficient aniseikonia (approximately $16 \%$ ) to prevent achievement of optimal binocularity. ${ }^{.3}$

Intraocular lenses as a first step or in cases of contact lens intolerance have a role in the treatment of the paediatric aphake. It has been our experience that children generally tolerate intraocular lenses well and that flexible anterior chamber implants are associated with fewer short term complications than posterior chamber intraocular lenses (mean follow up 2.4 years). In 19 of the 20 children the implants are stable, the eyes quiet, and the optical pathway to the retina clear. The visual outcome in non-traumatic cataracts depended chiefly on the severity of amblyopia at the time of surgery and compliance with postoperative occlusion therapy.

While contact lenses remain the initial treatment of choice in uniocular cataracts in infancy, intraocular lenses are well tolerated and have a role in the treatment of contact lens failures and older children. Flexible anterior chamber lenses may be preferred to posterior chamber implants for the treatment of children under 6 years old in view of their superior performance in this and other series.

\section{References}

1 Costenbader FD, Albert DG. Conservatism in the management of congenital cataracts. Arch Ophthalmol 1957: 58: 426-30.

2 Parkes MM, Hiles DA. Management of infantile cataracts. $A m$ J Ophthalmol 1967; 63: 10-9.

3 Ryan SJ. Maumenee AE. Unilateral congenital cataracts and their management. Ophthalmic Surg 1977; 8: 35-9.

4 Shapiro A. Soll D, Zaubermann H. Functional results after removal of unilateral cataracts in children under the age of 14 years. Metab Ophthalmol 1978; 2: 311-3.

5 Beller R, Hoyt CS, Marg E, Odom JV. Good visual function after neonatal surgery for congenital monocular cataracts. Am J Ophthalmol 1981; 91: 559-65.

6 Pratt-Johnson J, Tillson G. Visual results in congenital cataract surgery performed under the age of one year. Can J Ophthalmol 1981; 16: 19-21.

7 Robb RM, Mayer DL, Moore BD. Results of early treatment of unilateral congenital cataracts. J Pediatr Ophthalmol Strabismus 1987: 24: 178-81.

8 Birch EE, Stager DR. Prevalence of good visual acuity following surgery for congenital unilateral cataract. Arch Ophthalmol 1988: 106: 40-3.

9 Hoyt CS. The optical correction of pediatric aphakia. Arch Ophthalmol 1986; 104: 651-2.

10) Morris JA, Taylor D. Rogers JE, Vaegan J, Warland J. Contact lens treatment of aphakic infants and children. $J \mathrm{Br}$ Contact Len. Assoc 1979; 2: 22-30. 
11 Taylor D, Migdal C. Cataracts in infancy. In: Taylor D, Wybar K, eds. Pediatric ophthalmology: current concepts. New York: Dekker, 1983: 143-57.

12 Epstein RJ, Fernandes A, Gammon A. The correction of aphakia in infants with hydrogel extended-wear contact lenses: corneal studies. Ophthalmology 1988; 95: 1102-6.

13 Hiles DA. Visual acuities of monocular IOL and non-IOL aphakic children. Ophthalmology 1980; 87: 1296-300.

14 BenEzra D, Paez JH. Congenital cataract and intraocular lens. Am J Ophthalmol 1983; 96: 311-4.

15 Aron JJ, Aron-Rosa D. Intraocular lens implantation in unilateral congenital cataract: a preliminary report. $J A m$ Intraocul Implant Soc 1983; 9: 306-8.

16 Menezo JL, Taboada J. Assessment of intraocular lens implantation in children. J Am Intraocul Implant Soc 1982; 8: 131-5.

17 Blunmenthal M, Yalon M, Treister G. Intraocular lens implantation in traumatic cataract in children. $J$ Am Intraocul Implant Soc 1983; 9: 40-1.

18 Hiles DA. Intraocular lens implantation in children with monocular cataracts 1974-1983. Ophthalmology 1984; 91: 1231-7.

19 Binkhorst CD, Gobin MH. Congenital cataract and lens implantation. Ophthalmologica 1972; 164: 392-7.

20 Maida JW, Sheets JH. Pseudophakia in children: a review of results of eighteen implant surgeons. Ophthalmic Surg 1979; 10: 61-6.

21 Hiles DA. Watson BA. Complications of implant surgery in children. J Am Intraocul Implant Soc 1979; 5: 24-31.

22 Sinskey RM, Patel J. Posterior chamber intraocular lens implants in children: report of a series. $J$ Am Intraocul Implant Soc 1983: 9: 157-60.

23 Hiles DA. Hered RW. Modern intraocular lens implants in children with new age limitations. J Cataract Refract Surg 1987; 13: $493-7$
24 Frey T, Friendly D, Wyatt D. Re-evaluation of monocular cataracts in children. Am J Ophthalmol 1973; 76: 381-8.

25 Kushner BJ. Visual results after surgery for monocular juvenile cataracts of undetermined onset. Am J Ophthalmol 1986; 102: 468-72.

26 Rao GN. Complications due to daily wear soft contact lenses. In: Dabezies $\mathrm{O} \mathrm{Jr}$, ed. Contact lenses: the CLAO guide to basic science and clinical practice. Orlando: Grune and Stratton, 1984: 2: Ch 42.

27 Lemp MA, Gold JB. The effects of extended-wear hydrophilic contact lenses on the human corneal epithelium. $A m \mathrm{~J}$ Ophthalmol 1986; 101: 274-7.

28 Schoessler JP. Corneal endothelial polymegathism associated with extended wear. Int Contact Lens Clin 1983; 10: 148-55.

29 Morgan KS, McDonald MB, Hiles DA, et al. The nationwide study of epikeratophakia for aphakia in children. $A m \mathrm{~J}$ Ophthalmol 1987; 103: 366-74.

30 Morgan KS, McDonald MB, Hiles DA. The nationwide study of epikeratophakia for aphakia in older children. Ophthalmology 1988; 95: 526-31.

31 Katsumi O, Miyanaga $\mathrm{Y}$, Hirose $\mathrm{T}$, Okuno $\mathrm{H}$, Asaoka I. Binocular function in unilateral aphakia, correlation with aniseikonia and stereoacuity. Ophthalmology 1988; 95: 1088-93.

32 Reynolds JD, Hiles DA, Johnson BL, Biglan AW. A histopathological study of bilateral aphakia with a unilateral intraocular lens in a child. Am J Ophthalmol 1982; 93: 289-93.

33 Ogle KN, Burian HM, Bannon RE. On the correction of unilateral aphakia with contact lenses. Arch Ophthalmol 1958; 59: 639-52.

Accepted for publication 24 April 1989. 